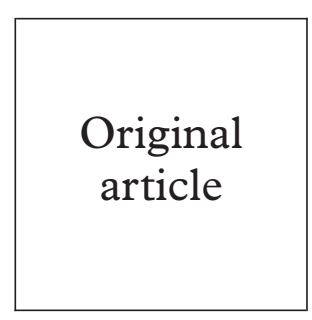

\title{
Sexual behaviour among youths at high risk for HIV-1 infection in Dar es Salaam, Tanzania
}

\author{
D Mwakagile, E Mmari, C Makwaya, J Mbwana, G Biberfeld, F Mhalu, E Sandström
}

Objectives: To investigate sex specific sexual behaviour in youths visiting a youth clinic for sexual and reproductive health in Dar es Saalam.

Methods: A questionnaire was administered to a random sample of youths between 10 and 24 years of age attending the youth health clinic in Dar es Saalam. The clinical investigation included testing for syphilis and HIV-1 antibodies

Results: 1423 youths attended the clinic between September 1997 and August 1998. The study population comprised $213(53.5 \%)$ males and 185 (46.5\%) females. 97 (24.4\%) were below 20 years. The mean age at coitarche was 16.5 and 17.0 years of age for males and females, respectively. The coitarche was involuntary in 15 females (8.6\%). 49.5\% males reported more than five lifetime partners compared with $14.1 \%$ for females $(\mathrm{p}<0.0001)$. Males reported recent partners to be 2.5 years younger, while females reported them to be 5.0 years older. No contraceptive use was reported by $29.7 \%$ of the males and $40.3 \%$ of females. $52.7 \%$ females had been pregnant and $26(14.1 \%)$ reported induced abortions. Genital discharge was found in $69.5 \%$ and $73.9 \%$ and GUD in $36.6 \%$ and $27.1 \%$ of males and females respectively. 12 males (5.9\%) and 43 females $(24.6 \%)$ were found to be HIV-1 infected. $13.8 \%$ of the females with only one lifetime partner were HIV-1 infected compared with $40.9 \%$ with more than five partners $(p=0.028)$.

Conclusions: Many youths in Dar es Salaam engage in sexual behaviours that put them at risk of unwanted pregnancies and STIs including HIV infection. Female youths were more likely to contract HIV infection than males. In African urban areas youth oriented clinics can have a pivotal role in HIV/STI prevention and control

(Sex Transm Inf 2001;77:255-259)

Keywords: youth; sexual behaviour; HIV

\section{Introduction}

The World Health Organization/UNAIDS estimated that during the year 19992.8 million people died of HIV/AIDS in the world, 2.2 million of whom were from sub-Saharan Africa; and 5.6 million people became newly infected with HIV, 3.8 million of whom were from sub-Saharan countries. ${ }^{1}$ Young people are at higher risk for sexually transmitted infections (STIs) including HIV infection than any other age group. ${ }^{2}$ The consequences of early HIV infection are both devastating for infected youths with the loss of many active years of life and to the entire society in that the infection spreads in the sexually most active group that for many years will fan the epidemic.

It is documented that STIs facilitate the transmission of HIV and that cure of symptomatic disease can reduce HIV transmission as demonstrated in Mwanza, Tanzania, with a low prevalence of HIV. ${ }^{3}$ However, that might not be the case in populations with a high prevalence of HIV. ${ }^{4}$ The situation among youth who are just initiating their sexual lives might be analogous to the situation in Mwanza.

Little is known about the sexual behaviour of urban youths in Tanzania. However, the age of initiation of vaginal intercourse, subsequent frequency of partner change, and use of different kinds of contraception are key factors for the understanding of the transmission of STI including HIV, and for the prevention of disease. Young females are more at risk for infection than males of a similar age.
The aim of the present study was to gather information on the sexual behaviour among youths attending a youth health clinic in Dar es Salaam.

\section{Patients and methods}

STUDY SET-UP

The youth health clinic (YHC) opened in September 1997 at the infectious disease clinic (IDC) near the central railway station at the centre of Dar es Salaam, a city of about 3 million inhabitants.

The YHC is open to all youths between 10 and 24 years of age.

The clinic was staffed with one medical officer, three clinical officers, three nurses, and one counsellor.

QUESTIONNAIRE AND DATA COLLECTION A standardised questionnaire was filled in by the investigating clinical officer during the visit following informed oral consent.

\section{CLINICAL INVESTIGATION}

External genital examination was complemented with a speculum examination in females. Bedside light microscopy was not available. The diagnosis and treatment of the STIs other than HIV and syphilis was by a syndromic algorithm. HIV pretest and post-test counselling was given to all youths. HIV seropositive patients were given an appointment in 1-2 weeks for additional counselling and referral to an appropriate nongovernmental organisation.
Accepted for publication 10 May 2001 
Table 1 Demographic characteristics the study population of youths with STIs in Dar es Salaam

\begin{tabular}{|c|c|c|c|c|c|}
\hline & \multicolumn{2}{|c|}{ Males $(n=213)$} & \multicolumn{2}{|c|}{ Females $(n=185)$} & \multirow[b]{2}{*}{ Total ( $p$ value) } \\
\hline & No & $\%$ & No & $\%$ & \\
\hline Sex & 213 & 53.5 & 185 & 46.5 & 398 \\
\hline \multicolumn{6}{|l|}{ Marital status } \\
\hline Single & 197 & 92.5 & 117 & 63.2 & $314(\mathrm{p}<0.0001)$ \\
\hline Married monogamously & 10 & 4.7 & 45 & 24.3 & $55(\mathrm{p}<0.0001)$ \\
\hline Married polygamously & 0 & & 7 & 3.8 & 7 \\
\hline Cohabiting & 4 & 1.9 & 8 & 4.3 & 12 \\
\hline Divorced & 2 & 0.9 & 3 & 1.6 & 5 \\
\hline Widowed & 0 & & 1 & 0.5 & 1 \\
\hline Separated & 0 & & 2 & 1.1 & 2 \\
\hline \multicolumn{6}{|l|}{ Occupation } \\
\hline Skilled labour & 20 & 9.4 & 5 & 2.7 & $25(\mathrm{p}<0.001)$ \\
\hline Petty trade & 147 & 69.0 & 47 & 25.4 & $194(\mathrm{p}<0.0001)$ \\
\hline Student & 31 & 14.6 & 33 & 17.8 & 64 \\
\hline Jobless & 11 & 5.2 & 45 & 24.3 & $56(\mathrm{p}<0.0001)$ \\
\hline Housewife & - & - & 50 & 27.0 & 50 \\
\hline Other & 2 & 0.9 & 6 & 3.2 & 8 \\
\hline Adolescents & 47 & 22.1 & 50 & 27.0 & 97 (NS) \\
\hline Young adults & 165 & 77.5 & 132 & 71.4 & 297 \\
\hline
\end{tabular}

Table 2 Syndromic diagnosis

\begin{tabular}{llllll}
\hline & $\begin{array}{l}\text { Males, } \\
(n=213)\end{array}$ & $\begin{array}{l}\text { Females, } \\
(n=185)\end{array}$ & $(\%)$ & Total \\
\hline $\begin{array}{l}\text { Syndromic diagnosis } \\
\text { UDS }\end{array}$ & 129 & 60.6 & - & - & 129 \\
VDS & - & - & 124 & 67.0 & 124 \\
GUD & 59 & 27.7 & 31 & 16.8 & 90 \\
UDS+GUD & 19 & 8.9 & - & - & 19 \\
VDS+GUD & - & - & 19 & 10.3 & 19 \\
Syphilis & 1 & 0.5 & 1 & 0.5 & 2 \\
PID & 0 & 0 & 2 & 1.1 & 2 \\
Other & 5 & 2.3 & 6 & 3.2 & 11 \\
Counsel & 0 & 0 & 1 & 0.5 & 1 \\
None/missing & 0 & 0 & 1 & 0.5 & 1 \\
\hline
\end{tabular}

UDS = urethral discharge syndrome, VDS = vaginal discharge syndrome, GUD = genital ulcer disease, PID = pelvic inflammatory disease.

LABORATORY METHODS

All study patients were bled for syphilis and HIV-1 serology following informed consent. The sera were tested by the venereal disease research laboratory (VDRL) (Murex Biotech Ltd, Dartford, UK) test and if positive confirmed by Treponema pallidum particle agglutination (TPPA) (Fujirebio Inc, Tokyo, Japan) test. Testing for HIV-1 was by Behring plus HIV-1\&2 ELISA (Behring Diagnostics $\mathrm{GmbH}$, Marburg, Germany) and those found

Table 3 Sexual and contraceptive history of youths with STIs in Dar es Salaam

\begin{tabular}{llllll}
\hline & Males, No & $(\%)$ & Females, No & $(\%)$ & Total $(p$ value $)$ \\
\hline Early coitarche & $63 / 211$ & 29.9 & $44 / 177$ & 24.9 & $107(\mathrm{p}=0.30)$ \\
Involuntary coitarche & $3 / 200$ & 1.50 & $15 / 175$ & 8.6 & $18(\mathrm{p}<0.001)$ \\
Contraception (ever used) & & & & & \\
$\quad$ None & $55 / 186$ & 29.6 & $64 / 159$ & 40.3 & $119(\mathrm{p}=0.04)$ \\
$\quad$ Condom & $128 / 186$ & 68.8 & $59 / 159$ & 37.1 & $187(\mathrm{p}<0.0001)$ \\
$\quad$ Pills & $8 / 186$ & 4.3 & $20 / 159$ & 12.6 & 28 \\
$\quad$ IUD & 0 & 0 & $2 / 159$ & 1.3 & 2 \\
$\quad$ Traditional & $4 / 186$ & 2.2 & $1 / 159$ & 0.6 & 5 \\
Sexual partners at present & & & & & \\
$\quad$ 1 & $141 / 184$ & 76.6 & $140 / 170$ & 82.4 & $281(\mathrm{NS})$ \\
$\quad$ 2-5 & $42 / 184$ & 22.8 & $29 / 170$ & 17.1 & 71 \\
$\quad$ Sex partners past 6 months & $1 / 184$ & 0.5 & $1 / 170$ & 0.6 & 2 \\
$\quad$ & & & & & \\
$\quad$ 2-5 & $80 / 200$ & 40.0 & $107 / 171$ & 62.6 & $187(\mathrm{p}<0.0001)$ \\
$\quad$ >5 & $109 / 200$ & 54.5 & $64 / 171$ & 37.4 & $173(\mathrm{p}=0.001)$ \\
Sexual partners ever & $11 / 200$ & 5.5 & 0 & 0 & $11(\mathrm{p}=0.0001)$ \\
$\quad$ 1 & & & & & \\
$\quad$ 2-5 & $9 / 210$ & 4.3 & $37 / 177$ & 20.9 & $46(\mathrm{p}<0.0001)$ \\
$\quad$ T5 & $97 / 210$ & 46.2 & $116 / 177$ & 65.5 & $213(\mathrm{p}=0.0001)$ \\
$\quad$ Type of sex practised & $104 / 210$ & 49.5 & $25 / 177$ & 14.1 & $129(\mathrm{p}<0.0001)$ \\
$\quad$ Penile-vaginal & & & & & \\
$\quad$ Penile-anal & $202 / 204$ & 100 & $175 / 176$ & 99.4 & 377 \\
$\quad$ Penile-oral & $7 / 204$ & 3.4 & $9 / 176$ & 5.1 & $16(\mathrm{p}=0.56)$ \\
$\quad$ Masturbation & $15 / 204$ & 7.4 & $40 / 176$ & 22.7 & $55(\mathrm{p}<0.0001)$ \\
& $18 / 204$ & 8.8 & $0 / 176$ & 0 & $18(\mathrm{p}<0.0001)$ \\
\hline
\end{tabular}

to be positive were retested by Wellcozyme Recombinant HIV-1 ELISA (Murex Biotech Ltd, Dartford, UK). HIV-1 positivity was determined only if a sample was positive in both tests. All sera with discordant results in the two ELISAs were tested by western blotting.

\section{STATISTICAL METHODS}

EPI-INFO (6.04b) was used for analysis and statistical significance tests were performed by using Fisher's exact test or $\chi^{2}$ values for categorical variables as indicated.

ETHICAL APPROVAL

The study has received approval from the research committee of the national AIDS control programme of the Ministry of Health in Tanzania.

\section{Results}

\section{DEMOGRAPHICS}

A total of 1423 youths attended the YHC between September 1997 and August 1998. Of these, $398(28.0 \%)$ were randomly recruited into the study; $213(53.5 \%)$ were males and 185 were females. For the purpose of this study, an adolescent is below 20 years, whereas a young adult is between 20 and 24 years of age. Forty seven $(22.1 \%)$ and $50(27.0 \%)$ were adolescent males and females, respectively (table 1). Most of the males were single, while many females were married or cohabiting (table 1), even female adolescents.

REASONS FOR ATTENDANCE

All males and $93.4 \%$ females said they attended the clinic because of "illness"; 10 females attended as contacts of males with STI. Most had a clinical complaint (see table 2).

The commonest source of information about the clinic for both males and females was a friend followed by the radio for both sexes, and sexual contacts for females.

SEXUAL HISTORY AND PRACTICE

The mean and median age at menarche was 14.9 (SD 1.54) and 15.0, respectively, while for spermarche (the first, often nocturnal, ejaculation; balehe) it was 15.7 (SD 1.95) and 16.0, respectively. The mean age at coitarche was 16.5 (SD 2.56) and 17.0 (SD 2.01) for males and females, respectively.

Many youths, $24.9 \%$ of the females and $29.9 \%$ of the males, had early coitarche, below 16 years of age $(p=0.30)$ (table 3$)$. The coitarche was reported to have been involuntary in $15(8.6 \%)$ of the females. Six males and eight females reported to have been raped at the sexual encounter that they thought was the cause of the presenting symptoms.

One lifetime sexual partner was reported by $4.3 \%$ of the males and $20.9 \%$ of the females ( $p>0.0001$ ), while $49.5 \%$ of the males and $14.1 \%$ of the females had had more than five lifetime sexual partners $(p<0.0001)$. Adolescents of both sexes had a similar number of 
Table 4 HIV-1 and syphilis infection

\begin{tabular}{llllll}
\hline & Males, No & (\%) & Females, No & (\%) & Total ( $p$ value) \\
\hline HIV-1 seropositive/tested & & & & & \\
$\quad$ Total & $12 / 203$ & 5.9 & $43 / 175$ & 24.6 & $55(\mathrm{p}<0.0001)$ \\
$\quad$ Adolescents & $0 / 45$ & 0 & $8 / 53$ & 15.1 & $8(\mathrm{p}=0.007)$ \\
Young adults & $12 / 158$ & 7.6 & $35 / 122$ & 28.7 & $47(\mathrm{p}<0.0001)$ \\
Early coitarche & $4 / 62$ & 6.5 & $13 / 43$ & 30.2 & $17(\mathrm{p}=0.002)$ \\
1 lifetime partner & $0 / 8$ & 0 & $5 / 36$ & 13.9 & 5 \\
$2-5$ & $5 / 92$ & 5.4 & $28 / 110$ & 25.5 & $33(\mathrm{p}<0.0001)$ \\
$>5$ & $7 / 100$ & 7.0 & $9 / 22$ & 40.9 & $16(\mathrm{p}=0.0002)$ \\
Syphilis seropositive/tested & & & & & \\
Total & $11 / 213$ & 5.2 & $7 / 185$ & 3.8 & $18(\mathrm{NS})$ \\
Adolescents & $4 / 48$ & 8.3 & $4 / 53$ & 7.6 & 8 \\
Young adults & $7 / 165$ & 4.2 & $3 / 132$ & 2.3 & 10 \\
Early coitarche & $6 / 63$ & 9.5 & $3 / 44$ & 6.8 & 9 \\
1 lifetime partner & $1 / 9$ & 11.1 & $1 / 37$ & 2.7 & 2 \\
2-5 & $5 / 97$ & 5.2 & $3 / 116$ & 2.6 & 8 \\
$>5$ & $5 / 104$ & 4.8 & $3 / 24$ & 12.5 & 8 (NS) \\
\hline
\end{tabular}

partners over the past 6 months, while the older males had significantly more partners than the older females $(\mathrm{p}<0.001)$.

Males reported that their partners at coitarche were younger with a mean of 0.7 (SD 2.0) years, while females reported their male partners to be older, the mean being 5.3 (SD $5.1)$ years at coitarche $(p<0.001)$. At the sexual intercourse that could have led to the presenting complaints, males reported that their female partners were on average 2.5 (SD 3.2) years younger and females reported that their male partners were on average 5.0 (SD 5.0) years older $(\mathrm{p}<0.0001)$.

Penile-oral sex was reported by $7.4 \%$ of the males and by $22.7 \%$ of the females $(p<0.0001)$ and penile-anal sex by $3.4 \%$ and $5.1 \%$ of males and females, respectively $(\mathrm{p}=0.56)$. Only 18 $(8.8 \%)$ males reported masturbation (table 3$)$. Homosexual practice was reported by $2.3 \%$ of the males and $2.9 \%$ of the females (data not shown).

CONTRACEPTIVE USE

Many, $29.7 \%$ of the males and $40.3 \%$ of the females, claimed to have never used any contraceptive method ( $p=0.04) ; 68.8 \%$ of the males and $37.1 \%$ of the females $(p<0.0001)$ (table 3) reported condom use for contraception.

PREGNANCY AND ABORTIONS

Ninety six $(52.7 \%)$ females reported to have ever been pregnant while $44(24.1 \%)$ said they had had abortions. Twenty six women had had repeated abortions.

CONDOM USE

Over all, $69.3 \%$ and $68.8 \%$ of the males had ever used condoms for prevention of STIs and contraception, respectively. The corresponding figures for females were $60.3 \%$ and $37.1 \%$, respectively. Condom use was $42 \%$ among those who reported one sex partner and $71 \%$ in those who had more than five partners ( $\mathrm{p}=$ 0.0015).

Only about $10 \%$ of the youths, regardless of sex or age at coitarche, reported to have used a condom during the sexual encounter that they suspected had led to the presenting problem (data not shown).
DIAGNOSIS OF STI SYNDROMES

Most youths had syndromic diagnoses implicated in facilitating HIV transmission. In males urethral discharge syndrome $(69.5 \%)$ and genital ulcer disease, GUD, (36.6\%) were common. In females most had the corresponding syndromes, vaginal discharge syndrome $(73.9 \%)$ and GUD (27.1\%). Only two female youths were found with no STI syndrome (table 2).

HIV-1 INFECTION

Forty three (24.6\%) females and $12(5.9 \%)$ males were found to be HIV-1 seropositive $(p<0.0001)$ (table 4$)$. No male and $15.1 \%$ of the female adolescents ( $p=0.007)$ was HIV infected. There was no statistically significant correlation between age at coitarche and risk for HIV-1 infection.

In females with only one lifetime partner, $13.8 \%$ were infected, compared with $40.9 \%$ of those with more than five partners $(p=0.028)$. In females, there was a positive association with the length of sexual activity and HIV-1 seropositivity (mean 5.1 versus 3.4 years, $\mathrm{p}=$ 0.0098 ) and also with the total number of sexual partners $(\mathrm{p}<0.052)$.

Among ever married or cohabiting females, $21.0 \%$ were HIV seropositive, compared with $27.0 \%$ of the single females $(\mathrm{p}=0.483)$.

In males, there was no significant difference in length of sexual activity (6.0 versus 4.7 years) and HIV-1 seropositivity $(p=0.07)$, nor with the number of sex partners.

HIV-1 seropositive females did not have coitarche with significantly older men (mean age difference 6.2 (SD 7.3) years) than seronegative females (mean age difference 5.0 (SD 4.2) years), nor did they have significantly older male partners at the latest sexual intercourse suspected to have caused the presenting infection (mean age difference 4.5 (SD 6.4) versus 4.9 (SD 4.1) years).

There was no association between oral or anal sex and HIV-1 seropositivity ( $p=0.64$ and $\mathrm{p}=1.0$, respectively).

Genital ulcers were found more often in seropositive males, 8/12 (66.67\%), and females, $18 / 43(41.86 \%)$, than in seronegative males, 65/191 (34.03\%), and females, $28 / 132$ $(21.21 \%), p=0.03$ and $p=0.001$, respectively.

None of the studied had antibodies against HIV-2.

SYPHILIS

There was no statistically significant difference in prevalence of active syphilis between females $(3.8 \%)$ and males $(5.2 \%)$, or between females and males who were adolescents $(7.6 \%)$ and $(8.3 \%)$ or who had had early coitarche $(6.8 \%)$ and $(9.5 \%)$ respectively (table 4$)$. Males with active syphilis had had an earlier coitarche (mean 14.9 (SD 3.0) years) compared with males without it (mean 16.6 (SD 2.5) years) ( $\mathrm{p}$ $=0.02$ ), while there was no difference among the females. There was no significant statistical difference in the number of years of coital activity in those with or without active syphilis in either sex, nor was there a correlation with the number of sex partners in males. However, 
females with six or more partners had an increased risk of contracting syphilis $(12.5 \%$ compared with $2.6 \%)(\mathrm{p}=0.046)$.

Eleven males and five females reported to have had a previously diagnosed STD and that was not predictive of current syphilis or HIV.

There was no association between oral or anal sex and syphilis.

Six of the $377(1.6 \%)$ youths had both HIV-1 and active syphilis $(\mathrm{p}<0.055)$.

\section{Discussion}

The fact that the YHC attracted 1423 youths in its first year of existence is a positive finding. The high prevalence of STD syndromes demonstrates the need for youth friendly services. The acceptability of the clinic was evidenced by the frequent reports that youths had heard about the clinic through friends. Since many of females were married or cohabiting and had already started their reproductive life a youth clinic in Dar es Salaam has to take this into account.

The findings cannot be generalised to all youths in Dar es Salaam but are limited to youths who had genital symptoms were motivated to seek medical care at a STD clinic. Despite the sensitive nature of the questions the response rate was very high.

All male youths and all but two female youths had one or more STI diagnoses by the syndromic approach which are associated with increased risk of HIV transmission. ${ }^{5} 6$

It is particularly disturbing that GUD was found in many youths $(36.6 \%$ and $27.1 \%$ of the males and females, respectively). ${ }^{7}$ However, despite the high prevalence of STI in this population, only 11 males and five females reported that they were aware of a previous STI.

Postponing initiation of sexual intercourse has been advocated as a means to halt HIV transmission. The mean age at coitarche of 16.5 and 17.0 years for males and females, observed in this study compares very well with what has been demonstrated by others in a variety of countries ${ }^{8}$ and does not indicate that this heavily infected population started to have sexual intercourse at an earlier age than age mates in other countries. Nor is it evident that those who started to have sex at 15 years of age or younger were at higher risk in this population.

Partner change is an important factor in the transmission of STI/HIV. There was a considerable potential for STI transmission since more than $50 \%$ of the males and females had had more than one partner over the past 6 months and $23 \%$ of the males and $17 \%$ of the females reported an ongoing relation with more than one partner. The observation that $40.9 \%$ of females with five or more partners were HIV infected underscores vulnerability of young women. Despite the high prevalence of STDs only $10 \%$ of the youths reported to have used a condom during the sexual encounter that was suspected to have caused the current problem.

Monogamy is often advocated to reduce the transmission of STI/HIV. Of the females with only one lifetime sexual partner, $13.8 \%$ were HIV-1 seropositive, indicating that their first sexual partners infected them. It is proposed that adherence to one partner in marriage is protective for STI/HIV. However, marital status was neither protective nor imposed a special risk of HIV infection among young females.

The most appalling finding in this study is that in this young age group, $24.6 \%$ and $5.9 \%$ of the females and males, respectively, are already HIV-1 infected. A similar sex discrepancy was found among schoolchildren in northern Tanzania. ${ }^{9}$ The higher infection rate in the females observed in this study is particularly remarkable in that they were less sexually experienced and had considerable fewer sexual partners than their male counterparts. These findings clearly indicate that young females are more vulnerable to HIV-1 infection than males. The reason for this has been attributed to the increased susceptibility of the female, which however was not substantiated in the Rakai study where HIV transmission was the same regardless of the sex of the first infected in discordant couples. ${ }^{10}$ It is probable that HIV-1 infection is spread into this young population of females by older males as the females reported the age difference between them and their sex partners at coitarche to be 5.3 years and at the latest sexual intercourse to be 5.0 years, while males reported that the age difference at coitarche to be on average 0.7 years and as at the latest sexual intercourse 2.5 years. This finding is in concordance with other studies from sub-Saharan Africa. ${ }^{11}$ In this study there was no indication that much older men, "sugar daddies," transmitted HIV to young females.

This study demonstrates that youths at high risk for HIV can be reached and that there are great needs for counselling, provision of condoms/contraception, and STI services in this population.

This study received funding as a part of the TANSWED HIV Programme from the Swedish Development Cooperation Agency (SIDA), department for research Cooperation (SAREC), Stockholm, Sweden. We especially thank Esther Malakasuka, Merida Mtanda, Steven Massam, Charles Kagoma, Joan James, Mary Lyaruu, Marcelina Mashurano, Churchill Mchumaishoke, Christine Mkambula, and Jane Churchill Mchumaishoke, Christine Mkambula, and Jane
Masanje for their hard work to make this study feasible and for their commitment to the young people attending the clinic. We also thank Karin Edgardh for critically reviewing the manuscript.

1 Report on the global HIV/AIDS epidemic. UNAIDS/00 13E, ISBN 92-9173-000-9, Geneva: WHO, June 2000.

2 Bishop-Townsend V. STDs: screening, therapy, and longterm implications for the adolescent patient. Int $\mathcal{f}$ Fertil Menopausal Stud 1996;41:109-14

3 Grosskurth H, Mosha F, Todd J, et al. Impact of improved treatment of sexually transmitted diseases on HIV infection in rural Tanzania: randomised controlled trial. Lancet 1995;346:530-6

4 Gray RH, Wawer MJ, Sewankambo NK, et al. Relative risks and population attributable fraction of incident HIV associated with symptoms of sexually transmitted diseases and treatable symptomatic sexually transmitted diseases in Rakai District, Uganda. Rakai Project Team. AIDS 1999;13:2113-23

5 Laga M, Manoka A, Kivuvu M, et al. Non-ulcerative sexually transmitted diseases as risk factors for HIV-1 transmission in women: results from a cohort study. AIDS 1993;7: sion in 102

6 Martin HL, Richardson BA, Nyange PM, et al. Vaginal lactobacilli, microbial flora, and risk of human immunodeficiency virus type 1 and sexually transmitted disease acquisition. F Infect Dis 1999;180:1863-8. 
7 Plummer FA, Simonsen JN, Cameron DW, et al. Cofactors in male-female sexual transmission of human immunodeficiency virus type 1. F Infect Dis 1991;163:233-9.

8 Singh S, Wulf D, Samara R, Cuca YP. Gender differences in the timing of first intercourse: Data from 14 countries. International Family Planning Perspectives 2000, vol 26.

9 Tengia-Kessy A, Msamanga GI, Moshiro CS. Assessment of behavioural risk factors associated with HIV infection among youth in Moshi rural district, Tanzania. East Afr Med F 1998;75:528-32.

10 Konde-Lule JK, Wawer MJ, Sewankambo NK, et al. Adolescents, sexual behaviour and HIV-1 in rural Rakai district, Uganda. AIDS 1997;11:791-9.

11 Quinn TC, Wawer MJ, Sewankambo N, et al. Viral load and heterosexual transmission of human immunodeficiency virus type 1. Rakai Project Study Group. $N$ Engl $f$ Med 2000;342:921-9.

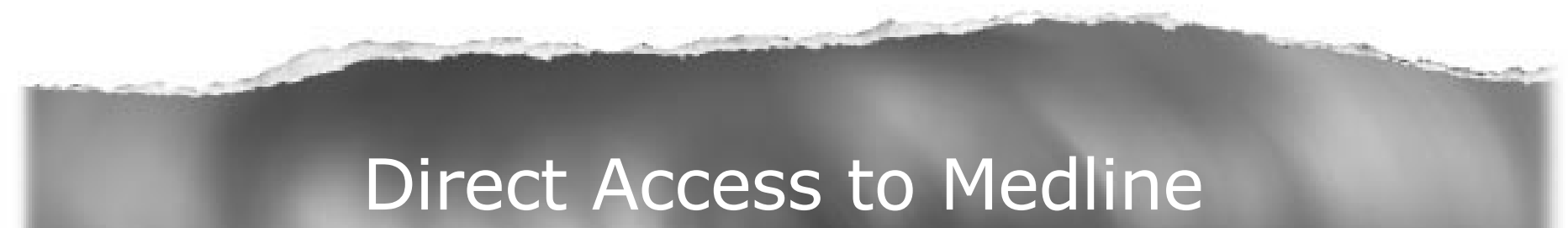

Medline

Link to Medline from the homepage and get straight into the National Library of Medicine's premier bibliographic database. Medline allows you to search across 9 million records of bibliographic citations and author abstracts from approximately 3,900 current biomedical journals.

www.sextransinf.com 